\title{
Effect of Cooling Efficiency on Emissions of Volatile Organic Compounds from Field Asphalt Pavement Mixtures
}

\author{
Huang Long-Sheng \\ Department of Distribution Management, Shu-Te University, Kaohsiung City 82445, Taiwan (R.O.C.)
}

(Received August 17, 2017; accepted January 23, 2018)

Keywords: asphalt mixture, cooling, volatile organic compounds (VOCs)

Hot mixed asphalt (HMA) in the paving and rolling phase may release all types of volatile organic compound (VOC) pollutants, but there are few studies on VOC emissions from in situ asphalt pavement mixtures. The purpose of this study was to evaluate the cooling variable effect on in situ new and recycled asphalt pavement (RAP) on VOC emission. Determination of VOCs in samples can be made by a gas chromatography mass spectrometer (GCMS). The results showed that the end temperature of RAP was about $5{ }^{\circ} \mathrm{C}$ lower than that of a new asphalt mixture during the cooling process. It required a longer amount of time for natural aggregate mixtures to lose heat and thus required more time for the pavement to be closed to traffic. After cooling to about $90-100{ }^{\circ} \mathrm{C}$, the pavement temperature gradient decreased gradually, indicating that the asphalt pavement mixtures' temperatures in the $90-100{ }^{\circ} \mathrm{C}$ range gradually reached a steady heat transfer process. In addition, higher temperatures affected the VOC emissions from any reclaimed asphalt mixture. The asphalt mixture continued to cool to below $100{ }^{\circ} \mathrm{C}$, and the acetone emission concentration gradually decreased. It was indicated that the temperature must be less than $100^{\circ} \mathrm{C}$ for asphalt pavement mixtures to reduce the risk of harm to human health.

\section{Introduction}

A bituminous binder has been widely used for asphalt paving materials. ${ }^{(1)}$ Most bitumen is applied at high temperatures. However, the heating process that results in volatile organic compound (VOC) emissions causes environmental pollution. ${ }^{(2)}$ This takes place from the moment of formation during production until utilization in road paving. ${ }^{(3)}$ In order to lower the viscosity that enables binding with aggregate and other applications, bitumen has to be heated prior to use in production. VOCs remaining in the bitumen mass are emitted during storage, transport, and the manufacture of asphalt mixtures. ${ }^{(4)}$

At present, there are few studies on the detailed characteristics of the presence of VOCs in bitumen fumes. Turk et al. showed that bituminous materials release VOCs, which are harmful to the environment and to construction workers. ${ }^{(5)}$ VOCs or non-methane hydrocarbons (NMHC) are organic chemicals that have a high vapor pressure and easy evaporation properties at ordinary room temperatures. ${ }^{(6,7)}$ Blankendaal et al. showed that VOCs released from 
bituminous materials occurred not only during the manufacturing process but also during the service period. ${ }^{(8)}$ Emissions of VOCs from hot bitumen have a direct effect on workers during bitumen production, transport of asphalt mixes, and road construction. Karakaya et al. proved that workers with weekly exposure to bitumen fumes had more health issues. ${ }^{(9)}$ In addition, Cui et al. showed that VOCs emissions are not only harmful to the pavement workers and the environment, but they also degrade the behavior of the bituminous binder. ${ }^{(10)}$

From this concept, reducing VOCs emissions from bituminous materials requires the use of bituminous materials with lower VOC contents. ${ }^{(1)}$ Agnes et al. studied emission rates for recycled asphalt pavement (RAP); the results showed that a full decrease in odor was nearly reached at a rate of just about $40 \% \mathrm{RAP}^{(12)}$ The environmental pollution impact of VOC emissions from bitumen should also be considered. However, few studies have identified VOC measurements for new and reclaimed asphalt pavements, or compared them with the corresponding results for VOC emissions.

The purpose of this study was to examine the effect of VOC emissions on property deteriorations of the bituminous binder on field testing of new pavement and RAP. The property changes of the asphalt binder resulting from VOC emissions were studied by cooling characterization and observation of the release of VOC emissions during paving, rolling, and transporting processes. At the same time, we observed the cooling variables for both new and RAP mixtures and noted VOC emissions to evaluate their effect on the asphalt mixtures.

\section{Materials and Methods}

\subsection{Basic properties of asphalt cement and aggregate}

The conventional and reclaimed aggregate samples applied in this study are obtained from a local plant corporation, Taiwan, and an AC-20 asphalt binder is used. The asphalt binder and aggregate properties are presented in Tables 1 and 2, respectively. The water absorption and Los Angeles abrasion of the reclaimed aggregate are higher than those of the natural aggregate. Reclaimed aggregate has a more porous structure, showing higher water-absorption and permeability than the natural aggregate. In addition, the Los Angeles abrasion ratio of the reclaimed aggregate is large and can easily be broken. This characteristic might lower aggregate interlocking and decrease the resistance to aggregate breakdown. However, the flat and elongated ratios of aggregate are used as a basic index for the evaluation to assess the bearing capacity of asphalt mixtures. Both the aggregate flat and elongated ratios are the same. It is indicated that reclaimed aggregates have similar bearing capacities.

\subsection{Aggregate gradation}

The mixtures used in this study included aggregate extracted from local plants, reclaimed asphalt pavement, and $\mathrm{AC}-20$ asphalt cement according to the classification of AASHTO M20. A dense mixture gradation curve was used for the development of the samples. Figure 1 shows the grading requirements of the natural and reclaimed aggregates. It is observed that 
Table 1

Asphalt binder properties.

\begin{tabular}{lccc}
\hline Test & Results & Criteria & Specification \\
\hline Penetration $\left(25^{\circ} \mathrm{C}, 100 \mathrm{~g}, 5 \mathrm{~s}, 0.1 \mathrm{~mm}\right)$ & 66 & $60-70$ & AASHTO M20 \\
Specific gravity & 1.035 & - & AASHTO T228 \\
Softening point $\left({ }^{\circ} \mathrm{C}\right)$ & 56 & $>50$ & AASHTO T36 \\
Ductility $\left(25^{\circ} \mathrm{C}, 5 \mathrm{~cm} / \mathrm{min}, \mathrm{cm}\right)$ & $100+$ & $>50$ & AASHTO T51 \\
Flash point $\left({ }^{\circ} \mathrm{C}\right)$ & $240+$ & $>232$ & AASHTO T48 \\
Viscosity $\left(60{ }^{\circ} \mathrm{C}\right.$, poise $)$ & 1860 & $2000 \pm 400$ & AASHTO M226 \\
Solubility $(\%)$ & 99.5 & $>99$ & AASHTO T44 \\
Mix temperature $\left(170 \pm 20 \mathrm{cSt},{ }^{\circ} \mathrm{C}\right)$ & 155 & - & ASTM D 2493 \\
Compaction temperature $\left(280 \pm 30 \mathrm{cSt},{ }^{\circ} \mathrm{C}\right)$ & 145 & - & AASHTO 2493 \\
\hline
\end{tabular}

AASHTO M20: Standard Specification for Penetration-Graded Asphalt Cement

AASHTO T228: Standard Method of Testing for Specific Gravity of Semi- Solid Asphalt Materials

AASHTO T36: Softening Point Test for Asphalt Binder

AASHTO T51: Ductility of Bituminous Materials

AASHTO T48: Standard Method of Testing for Flash and Fire Points by Cleveland Open Cup

AASHTO M226: Standard Specifications for Viscosity-Graded Asphalt Cement

AASHTO T44: Standard Method of Testing for Solubility of Bituminous Materials

ASTM D2493: Standard Viscosity-Temperature Chart for Asphalt

Table 2

New and reclaimed aggregate properties.

\begin{tabular}{|c|c|c|c|c|c|}
\hline Test & & Natural aggregate & Reclaimed aggregate & Criteria & Specification \\
\hline Specific gravity & & 2.61 & 2.43 & - & ASTM C127 \\
\hline Water absorption (\%) & & 1.67 & 1.90 & $<3$ & ASTM C127 \\
\hline Los Angeles abrasion (\%) & & 25.70 & 32.50 & $<40$ & AASHTO T96 \\
\hline \multirow{2}{*}{ Fractured } & $<3 \%$ surfaces & 20.19 & 23.25 & - & ASTM D5821 \\
\hline & $\geq 3 \%$ surfaces & 89.20 & 79.82 & - & ASTM D5821 \\
\hline Flat and elongate ratio & $\geq 1: 3$ & 6.91 & 6.82 & $<7$ & ASTM D4791 \\
\hline
\end{tabular}

ASTM C127-07: Standard Test Method for Density, Relative Density (Specific Gravity), and Absorption of Coarse Aggregate AASHTO T96: Standard Method of Testing for Resistance to Degradation of Small-Sized Coarse Aggregate by Abrasion and Impact in the Los Angeles Machine

ASTM D5821-01: Standard Test Method for Determining the Percentage of Fractured Particles in Coarse Aggregate ASTM D4791-10: Standard Test Method for Flat Particles, Elongated Particles, or Flat and Elongated Particles in Coarse Aggregate

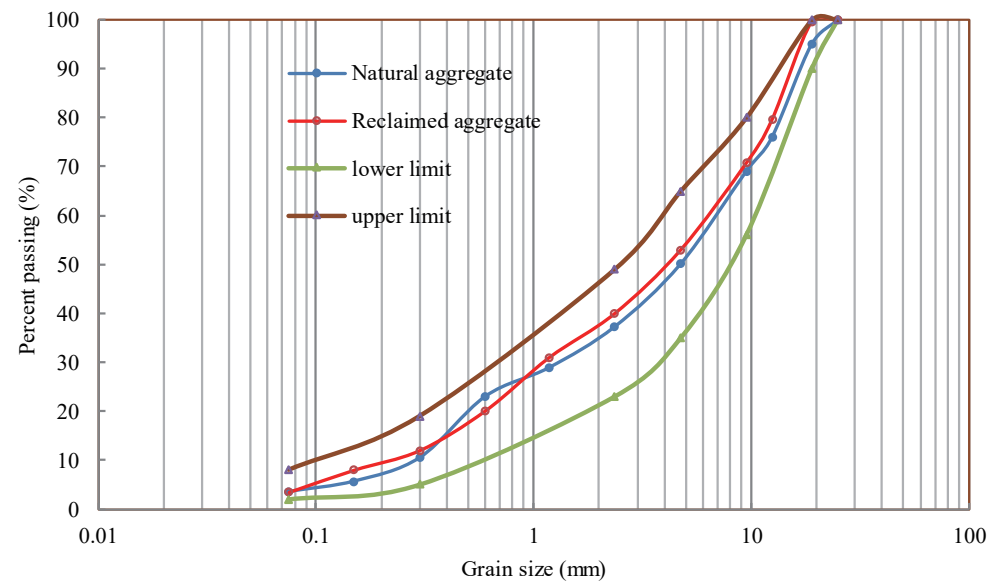

Fig. 1. (Color online) Grading requirements for natural and reclaimed aggregate mixes. 
the reclaimed aggregate grading requirements were finer than those of the new aggregate. However, the natural and reclaimed aggregates conformed to all sieve sizes of the gradation curve.

\subsection{Marshall mix design of asphalt mixture with natural and reclaimed aggregate}

The coarse aggregate, fine aggregate, and filler material should be proportional so as to fulfill the requirements of relevant standards. The aggregate gradation is regulated by ASTM D3515 specifications, and the nominal maximum size of aggregates is $19.5 \mathrm{~mm}$. In addition, $40 \%$ of the natural aggregate (both fine and coarse) is replaced by the reclaimed aggregate. The required quantity of the mix is taken so as to produce compacted bituminous mix specimens of approximately $63.5 \mathrm{~mm}$ thickness. $1200 \mathrm{~g}$ of aggregate and filler are required to produce the desired thickness.

The aggregate is heated to $170{ }^{\circ} \mathrm{C}$. The compaction mold assembly and rammer are cleaned and kept preheated at $155^{\circ} \mathrm{C}$. The bitumen is heated to $155^{\circ} \mathrm{C}$, and the required amount of the first trial bitumen is added to the heated aggregate and thoroughly mixed. All specimens are compacted on the basic of a heavy traffic volume design. Each side of the specimen is compacted 75 times, and the Marshall test is performed. The specimens are taken out of the mold after $24 \mathrm{~h}$ using a sample extractor.

Table 3 lists the Marshall testing results of both asphalt mixtures from the laboratory design and a sampling of the paver. Similar results are observed for the laboratory design and sampling of the paver on new and reclaimed asphalt mixtures. The new asphalt pavement mixture has a more optimum specific gravity, theoretical maximum specific gravity, and stability than the reclaimed asphalt pavement. It is indicated that the new asphalt pavement is better than the reclaimed pavement with a better load-bearing capacity. However, the Marshall testing results conformed to the ASTM D6927-15 specification for both types of asphalt pavement.

Table 3

Marshall testing results for asphalt mixtures.

\begin{tabular}{|c|c|c|c|c|c|}
\hline \multirow{2}{*}{ Test } & \multicolumn{2}{|c|}{ New } & \multicolumn{2}{|c|}{ Reclaimed } & \multirow{2}{*}{ Specification } \\
\hline & Lab design & Field sample & Lab design & Field sample & \\
\hline Optimum asphalt content (\%) & 5.28 & 5.20 & 4.98 & 4.96 & $4.0-7.0$ \\
\hline Target viscosity (poise) & 9800 & 9600 & 9800 & 9800 & $>8000$ \\
\hline Specific gravity & 2.62 & 2.61 & 2.532 & 2.38 & - \\
\hline Absorption (\%) & 0.06 & 0.05 & 0.05 & 0.03 & - \\
\hline Theoretical maximum specific gravity & 2.81 & 2.85 & 2.41 & 2.47 & - \\
\hline Stability (kgf) & 2380 & 2312 & 1658 & 1647 & $>816$ \\
\hline Flow $(0.25 \mathrm{~mm})$ & 11.6 & 11.5 & 11.3 & 11.4 & $8-14$ \\
\hline Unit weight & 2.37 & 2.30 & 2.32 & 2.31 & - \\
\hline Void $(\%)$ & 4.15 & 4.05 & 4.36 & 4.50 & $3-5$ \\
\hline Voids in mineral aggregate (VMA) (\%) & 15.27 & 13.8 & 16.07 & 16.30 & $\geq 13.0$ \\
\hline Voids filled with asphal (VFA) (\%) & 73 & 72 & 72 & 70 & $65-75$ \\
\hline
\end{tabular}




\subsection{Test asphalt pavement and measurement}

In this study, the test road sections are located inside the SHU-TE University, Kaohsiung City, Taiwan. The length and width of the test road sections are $250 \mathrm{~m}$ by $6 \mathrm{~m}$, respectively. The pavement thickness is $5 \mathrm{~cm}$. As shown in Fig. 2, the test road section is divided into two types: new and reclaimed asphalt mixtures.

The dense asphalt mixture is used in the test pavement. AC-20 grade is used as the asphalt mixture binder. The reclaimed aggregate is limited to $40 \%$ of the total weight of aggregate, and the maximum nominal grain size is $19 \mathrm{~mm}(3 / 4 \mathrm{in})$. Bitumen is a semisolid substance used primarily as the binder in asphalt production.

Compaction is the process by which the volume of air in a hot mixed asphalt (HMA) mixture is reduced by using external forces to reorient the constituent aggregate particles into a more closely spaced arrangement. This reduction in air volume produces a corresponding increase in HMA density. ${ }^{(13)}$ The compaction is divided into initial, complex, and final. The same roller is used for both test road sections. In each test section, the weight, amplitude, roller speed, and rolling number are maintained. At initial compaction, a two-axis three-wheel tandem roller, weighing 10 tons, is used. The pressure exerted by the driving wheel is $50 \mathrm{kgf}$ per centimeter in width, and a rolling speed of $3 \mathrm{~km} / \mathrm{h}$ is maintained. A pneumatic-tired roller is applied for the final compaction.

\subsubsection{Temperature measurements}

As shown in Fig. 2, the temperature measurement points are placed at different locations for both sections after the pavement construction is finished. The test locations are placed perpendicular to each other, 40, 80, and $120 \mathrm{~m}$ apart at each section in the axial direction. The temperatures are measured consecutively, starting from the beginning of the pavement construction and ending at the time when there is no apparent temperature change. The recording time is usually approximately $240 \mathrm{~min}$, using the CENTER309 temperature recorder with a temperature test rod, and then the rate of cooling is calculated.

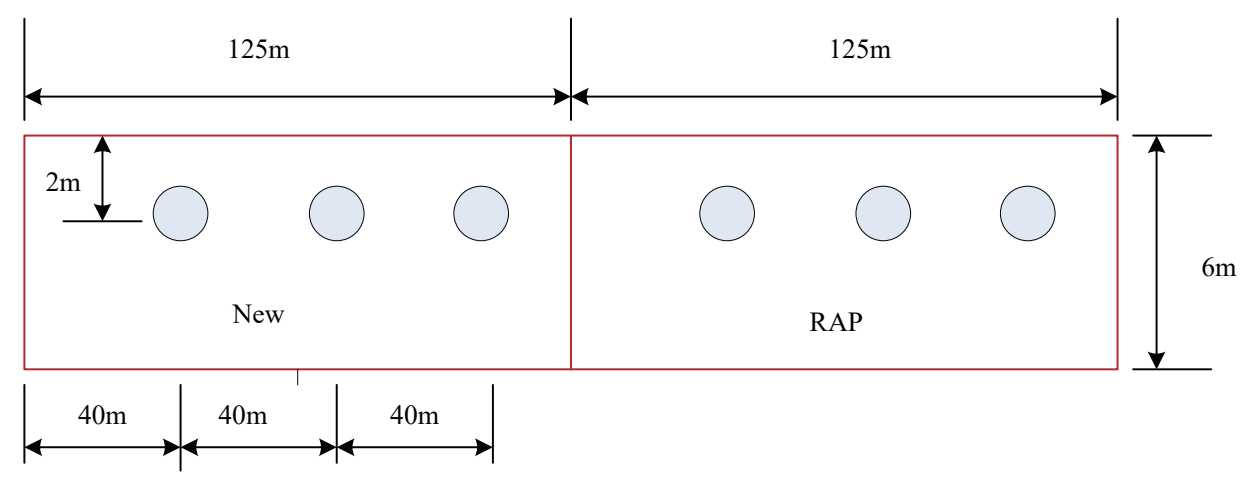

Fig. 2. (Color online) Test asphalt pavement plan. 


\subsubsection{Identification of volatile components by gas chromatography-mass spectrometry (GC-MS)}

In this study, we explored the effects of the release of VOCs in asphalt mixtures at a high temperature. The sample locations were the same as the temperature measurement points. As shown in Fig. 3, the thermal tube/gas chromatography mass spectrometry (TC-MS), which is an analytical method of identifying different volatile products, was used in this study to analyze VOC emissions from bituminous pavement.

The TC-MS test method was published in accordance with the announcement of stainless steel sampling by the Taiwan Environmental Protection Agency. The test procedure was used to collect air by instantaneous inhalation or fixed flow collection using a stainless sampling tube, which had been emptied beforehand. The air samples were collected by a freezing method, then cooled by thermal desorption to the front end of the gas chromatographic injection port. Finally, the contents of the volatile organic compounds in the samples were determined by GC-MS.

The test equipment is divided into sampling equipment and the gas chromatograph. In Fig. 4, the sampler's constant flow is set at $100 \mathrm{ml} / \mathrm{min}$ to perform high-atmospheric-pressure sampling. The stainless sampling tube volume is $6 \mathrm{~L}$. The flow meter controls the gas flow range from 0 to $100 \mathrm{ml} / \mathrm{min}$. The pressure gauge measures 0 to $760 \mathrm{~mm} \mathrm{Hg}$ vacuum pressure and 0 to 30 psig pressure. The gas chromatograph, as shown in Fig. 5, maintains the flow control through the thermal disrober to maintain a limited flow rate and controls the separation of the separation column when operating at elevated temperatures.

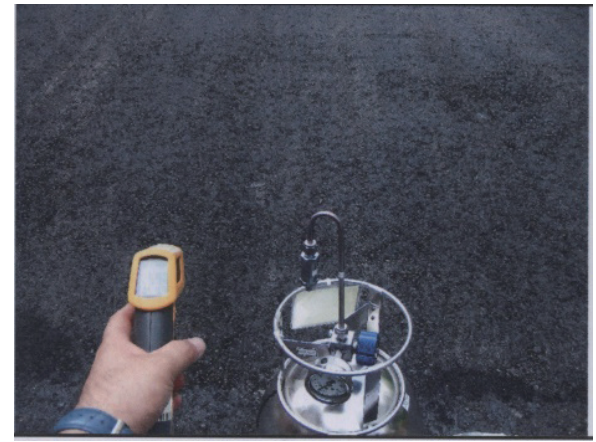

Fig. 3. (Color online) In situ temperature measurements and VOCs detected.

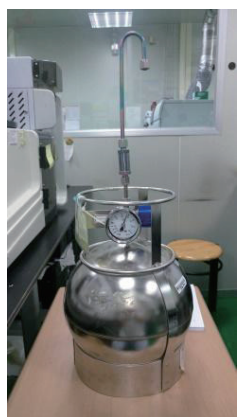

Fig. 4. (Color online) Sampler.

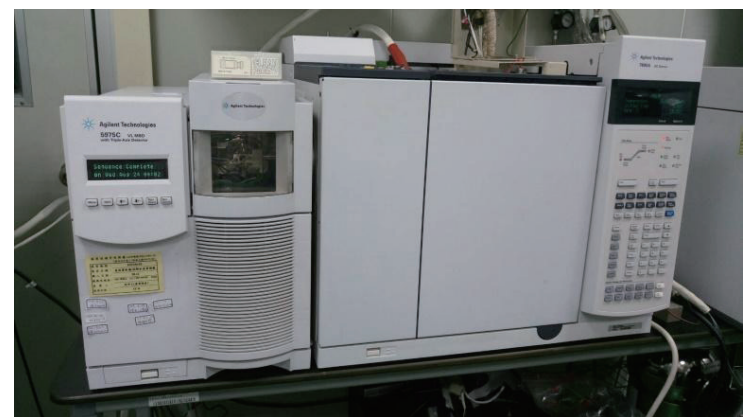

Fig. 5. (Color online) Gas chromatograph. 
In this study, the quantitative analysis of VOCs is carried out by using detection equipment to find the peak area and concentration, and then by the relative sensitivity of each relative response factor (RRF) and the average induction factor (AIF). The concentration of air is determined using Eq. 1 with the peak area measured using the compound:

$$
C=\frac{A_{x} \times C_{i s} \times D F}{A_{i s} \times R R F}
$$

$C$ : Concentration of test substance (ppbv)

$A_{x}$ : Main quantitative ion integral area of the analyte

$A_{i s}$ : Main quantification of the standard area of ionization

$C_{i s}$ : Internal standard addition concentration (ppbv)

$R R F$ : Relative average inductive factors of the analyte

$D F$ : Dilution factor, if not diluted, then $D F=1$

\section{Results and Discussion}

\subsection{Cooling potential of asphalt pavement mixture}

Figure 6 shows the temperature variations with time for natural and reclaimed aggregates in the field testing of asphalt mixture pavement. It can be seen that on the pavement surface, the cooling curves representing temperature variations for in situ asphalt mixtures containing $40 \%$ reclaimed aggregate are lower than those on the natural aggregate pavement. The temperatures on the surface are apparently affected largely by the surrounding air temperature. At the beginning of the paving, surface temperatures are about 148 and $152{ }^{\circ} \mathrm{C}$, with the surrounding air temperature at about $28{ }^{\circ} \mathrm{C}$. Since the surfaces are in contact with the atmosphere, the resulting temperatures decrease quickly. The temperatures for both pavement surfaces decrease rapidly and gradually stabilize after $50 \mathrm{~min}$. Heat insulation on natural aggregate mixtures is better than on those containing reclaimed aggregate. At the end of measurements at $240 \mathrm{~min}$, natural mixtures and those containing a $40 \%$ reclaimed aggregate mixture reached a stable condition with temperatures of 55 and $50{ }^{\circ} \mathrm{C}$, respectively. From this phenomenon, it would

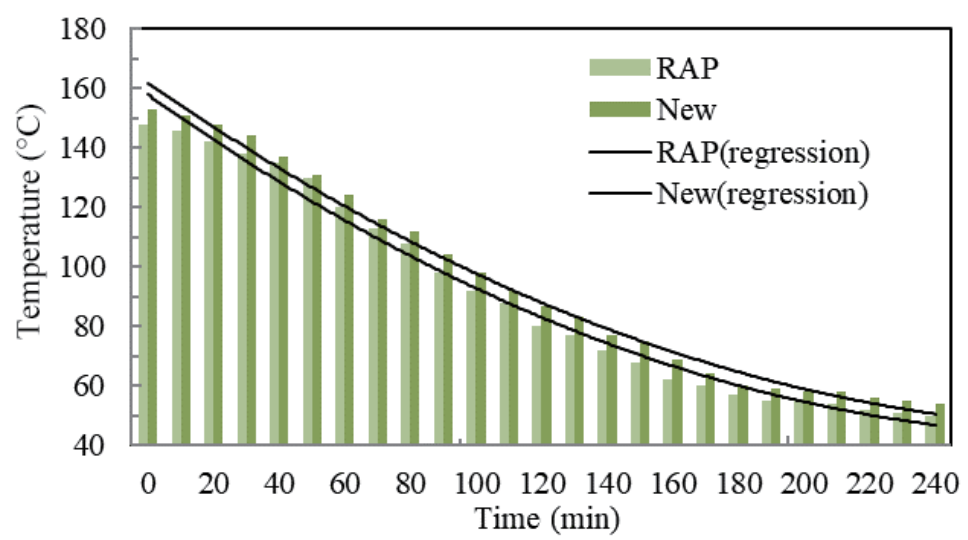

Fig. 6. (Color online) Effective thermal variation with natural and reclaimed aggregate asphalt pavements. 
require a longer time for natural aggregate mixtures to lose heat and thus require slightly more time before the new pavement could be open to traffic.

The gradation of a natural aggregate mixture contains a more coarse aggregate, and the reclaimed aggregate asphalt mixture uses a more fine aggregate, including the 4.76, 2.36, and 0.6 $\mathrm{mm}$ sieve sizes. The overall porosity of the natural aggregate asphalt mixture is greater. The effective thermal conductivity decreases with the decrease in the coarse aggregate content and the increase in the number of air voids. The effective thermal conductivity of asphalt mixtures is affected by the voids and the aggregate content. Similar trends were also observed by Chen et al. in their study. ${ }^{(14)}$

Figure 7 shows the calculated effective thermal gradient for natural and reclaimed aggregate asphalt pavement mixtures. It can be seen that the thermal cooling gradient increased with the increase in cooling time from $0 \mathrm{~min}$ (after paving) to about 100-120 min. However, the thermal cooling gradient gradually decreases with the decrease in cooling time until the pavement cooling time reaches a total of $240 \mathrm{~min}$. The reclaimed aggregate asphalt pavement cooling gradient is higher than that of the natural aggregate mixture pavement. Furthermore, it can be found that the asphalt pavement began to cool after being paved, and after about 100-120 min, its temperature range was between 80 and $90{ }^{\circ} \mathrm{C}$, which should be related to the distribution of the aggregate gradation void structure.

After the asphalt mixture paving process, the pavement surface temperature and atmospheric temperature were about 140 and $28{ }^{\circ} \mathrm{C}$, respectively. This temperature difference generated a heat transfer, with the pavement continuing to release heat and the inside of the pavement continuing to generate heat, resulting in the heat exchange effect. After decreasing to about 90-100 ${ }^{\circ} \mathrm{C}$, the temperature gradient decreased gradually, indicating that the asphalt pavement mixtures' temperatures in the $90-100{ }^{\circ} \mathrm{C}$ range gradually reached a steady heat transfer process.

The new and reclaimed asphalt mixture temperature gradients (Fig. 7) correspond to the cooling curve (Fig. 3), and the cooling time is about $100 \mathrm{~min}$, relating to the paving temperatures of the fresh and recycled asphalt mixtures of 90 and $95^{\circ} \mathrm{C}$, respectively. Because the natural aggregate asphalt mixture has a smaller void structure, the paving has a greater effect on the temperature, the cooling gradient is more moderate, and it may be necessary to extend the closed traffic time after paving.

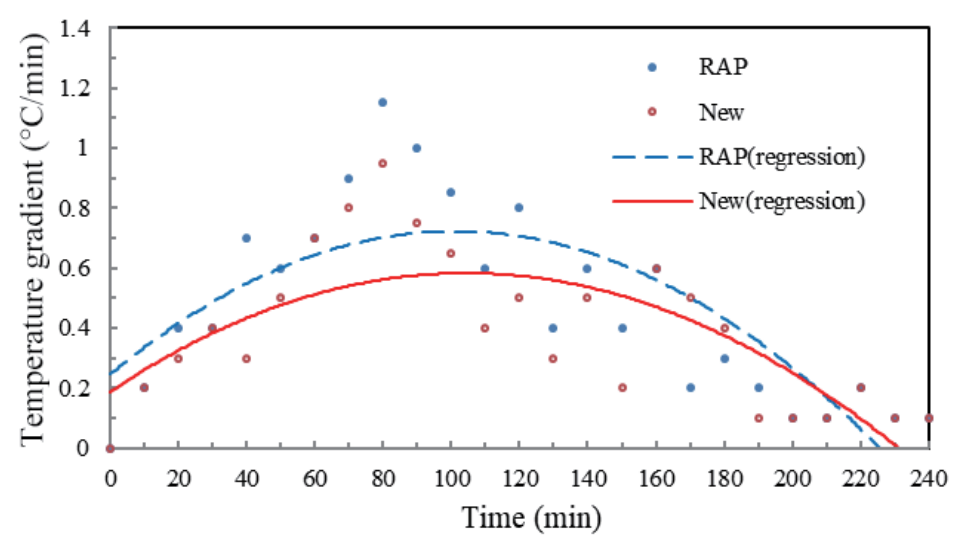

Fig. 7. (Color online) Trends of new and reclaimed asphalt mixture temperature gradients. 


\subsection{Measurement of VOCs in asphalt concrete mixtures}

In this study, we detected VOC emissions from field asphalt pavement, from the time the paving finished to $4 \mathrm{~h}$ later. According to the EPA's announcement regarding the method for the detection of VOCs in air, i.e the stainless sampling cartridge gas chromatographic mass spectrometer (NIEA A715.15), the detection content of the volatile compounds was calculated and detected once per hour. Tables 4 and 5 present VOC emissions based on field pavement cooling times. The asphalt mixtures were paved under high temperatures, and just after paving, the new aggregate asphalt mixture released volatile compounds, which are listed from most to least as follow: acetone, ethanol, trimethylbenzene, toluene, butanone, isopropyl alcohol, and so forth. The reclaimed aggregate asphalt mixture released acetone, trimethylbenzene, toluene, butanone, and benzene.

\subsection{Evolution and temperature of VOCs}

Figure 8 shows the intensity of acetone emissions versus conditioning temperatures for field bituminous pavement. The intensity of acetone emissions has a positive correlation with the temperature. A stronger ion current intensity means a higher ion emission. The reclaimed aggregate asphalt pavement has a higher acetone intensity. The acetone compound emission concentration increases rapidly when new or reclaimed asphalt pavement temperatures are higher than 100 and $80{ }^{\circ} \mathrm{C}$, respectively. It is indicated that higher temperatures have a noticeable effect on the emissions of VOCs from reclaimed asphalt mixture. Ilaria et al. (2017) found that direct aging was completely different from the original microstructure of the unaged

Table 4

VOCs in new asphalt pavement mixtures.

\begin{tabular}{lrlllllllllll}
\hline \multirow{2}{*}{ Time (h) } & \multicolumn{11}{c}{ Detection value (ppb) } \\
\cline { 2 - 13 } & $\mathrm{Ac}$ & $\mathrm{Bu}$ & $\mathrm{Di}$ & $\mathrm{Et}$ & $\mathrm{He}$ & $\mathrm{Be}$ & To & Ethy & Xy & Tr & Etha & Is \\
\hline 0 & 20.6 & 5.1 & 1.6 & 1.3 & 0.7 & 1.3 & 5.4 & 1.4 & 2.4 & 8.4 & 14.2 & 3.7 \\
1 & 7.9 & 1.1 & ND & 1.3 & ND & ND & 2.1 & ND & 0.4 & 0.6 & 3.9 & ND \\
2 & 6.6 & 1.1 & ND & ND & ND & ND & 2.0 & ND & ND & ND & ND & ND \\
3 & 6.1 & 0.8 & ND & ND & ND & ND & 1.3 & ND & ND & ND & ND & ND \\
\hline
\end{tabular}

Ac: acetone, Bu: butanone, Di: dichloromethane, Et: ethylacetate, He: heptane, Be: benzene,

To: toluene, Ethy: ethylbenzene, Xy: xylene, Tr: trimethylbenzene, Etha: ethanol, Is: isopropanol

Table 5

VOCs in reclaimed asphalt mixture pavement.

\begin{tabular}{lrccccccccccc}
\hline \multirow{2}{*}{ Time (h) } & \multicolumn{11}{c}{ Detection value $(\mathrm{ppb})$} \\
\cline { 2 - 13 } & $\mathrm{Ac}$ & $\mathrm{Bu}$ & $\mathrm{Di}$ & $\mathrm{Et}$ & $\mathrm{He}$ & $\mathrm{Be}$ & $\mathrm{To}$ & Ethy & Xy & Tr & Etha & Is \\
\hline 0 & 26.1 & 6.7 & ND & 1.9 & 0.5 & 5.4 & 6.9 & 2.4 & 5.1 & 15.1 & 4.5 & ND \\
1 & 11.3 & 1.3 & ND & 1.4 & ND & ND & 2.6 & ND & 0.4 & 0.4 & ND & ND \\
2 & 9.4 & 0.9 & ND & 1.3 & ND & ND & 2.5 & ND & ND & ND & 6.0 & ND \\
3 & 9.1 & ND & ND & 1.1 & ND & ND & 1.9 & ND & ND & ND & ND & ND \\
\hline
\end{tabular}

Ac: acetone, Bu: butanone, Di: dichloromethane, Et: ethylacetate, He: heptane, Be: benzene,

To: toluene, Ethy: ethylbenzene, Xy: xylene, Tr: trimethylbenzene, Etha: ethanol, Is: isopropanol 


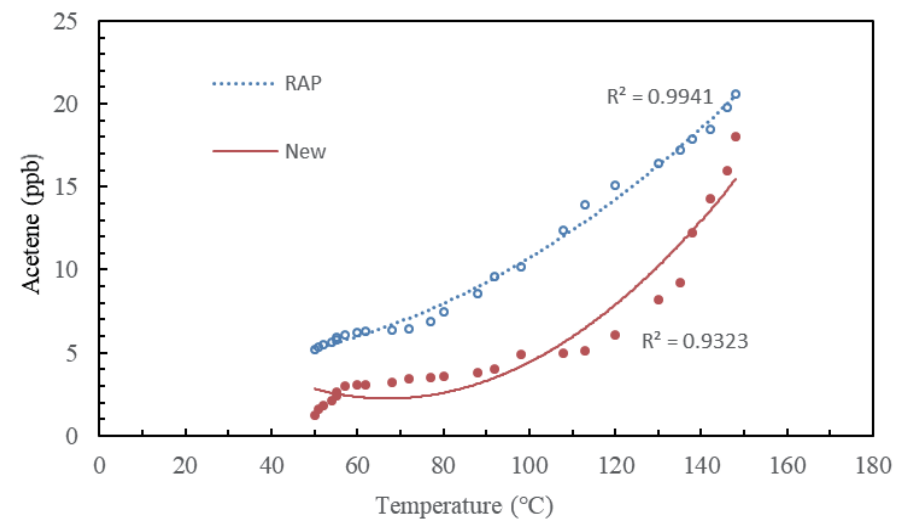

Fig. 8. (Color online) Relationship between temperature and acetone emissions for field asphalt pavement mixtures.

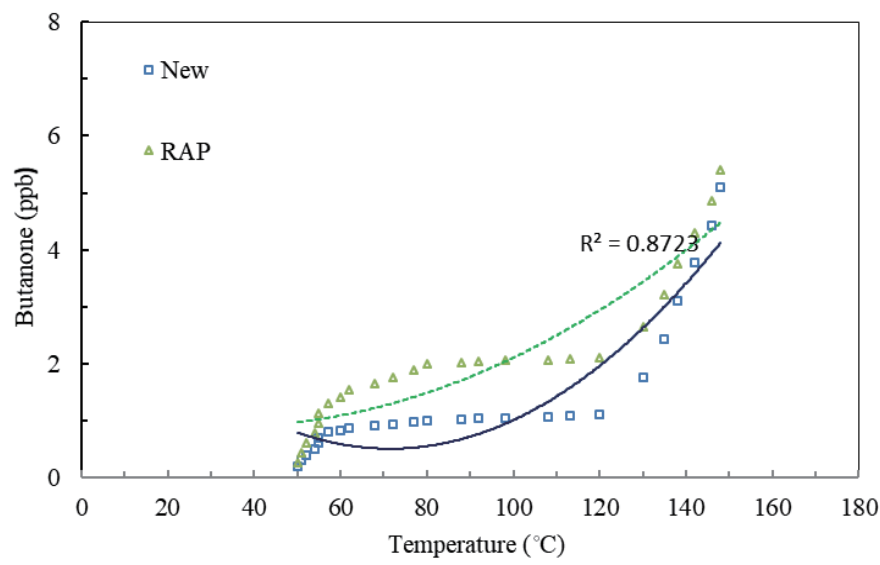

Fig. 9. (Color online) Relationships between temperature and butanone emissions for field asphalt pavement mixtures.

binder and any binder microstructures. ${ }^{(15)}$ The inhalation of acetone can cause dizziness, headaches, confusion, high blood pressure, nausea, vomiting, confusion, and coma. ${ }^{(15)}$ The Occupational Safety and Health Administration (OSHA) for the protection of workers in an 8-h day, 40-h week working environment states that the cumulative amount of acetone exposure cannot exceed $1000 \mathrm{ppm}$.

Figure 9 shows that the intensity of butanone emissions also has a positive correlation to temperature, but the emission intensity is lower than that for acetone emissions for both types of aggregate asphalt pavement. Under high temperature, the concentration of volatile organic compounds is mainly affected by the increase in temperature. The new asphalt mixture is in the high temperature range of $120^{\circ} \mathrm{C}$ or higher, the concentration of acetone is high, the temperature is lower than about $100{ }^{\circ} \mathrm{C}$, and the concentration gradually decreases, showing that acetone components decrease in concentration the high temperature stage. A high concentration of toluene will significantly harm human health, and at about $100{ }^{\circ} \mathrm{C}$, this harm will gradually decrease. 


\section{Conclusion}

VOC emissions cause environmental pollution and risk of harm to human health. The effect of asphalt composition conditions on the thermal properties of field asphalt pavement was investigated in this study. On the basis of the research results, the conclusions are listed as follows:

1. A new aggregate asphalt pavement mixture's overall temperature cooling trend is about $5{ }^{\circ} \mathrm{C}$ lower than that of a recycled asphalt concrete mixture. As the overall porosity of the fresh asphalt mixture is greater, when the pavement is at a high temperature, the outside air can penetrate easily into the aggregate, reducing the pavement temperature.

2. The total cooling record time is $240 \mathrm{~min}$ or the time it takes for the new and reclaimed aggregate asphalt pavements to complete cooling at about 50 and $54{ }^{\circ} \mathrm{C}$, respectively.

3. At first, the asphalt mixtures cooled quickly, and the new and reclaimed aggregate asphalt pavements had similar initial heat dissipation rates. However, the new asphalt mixture took longer than the fresh asphalt mixture to completely dissipate the heat, with an ending temperature of about $8-10{ }^{\circ} \mathrm{C}$, showing that the new asphalt mixture requires traffic to be closed off for a longer period of time than the reclaimed aggregate asphalt mixture.

4. By using a gas chromatogram with the fresh and recycled asphalt mixture at $0 \mathrm{~h}$ after paving, we found that both released bromochloromethane, difluorobenzene, chlorobenzene, and bromofluorobenzene. One hour after paving, acetone, trichlorofluoromethane, dichloromethane, methyl ethyl ketone, ethyl acetate, and heptane were released. Two hours after paving, difluorobenzene, toluene, and xylene were detected. Three hours after paving, bromochloromethane, difluorobenzene, and other gases were still found.

5. Asphalt pavement mixtures have the highest content of acetone but still show an acceptable concentration. In addition, new and recycled asphalt concrete pavement mixtures still contain butanone compounds after $3 \mathrm{~h}$, and the concentration of benzene compounds will still lead to carcinogenic risks, showing that there should be no long-term exposure to benzene compounds.

6. The asphalt mixtures had high exposure to temperatures above $120{ }^{\circ} \mathrm{C}$, and a high concentration of acetone was released. With continuous cooling to about $100{ }^{\circ} \mathrm{C}$, the acetone concentration gradually decreased.

\section{Acknowledgments}

This study was endorsed by the 2017 special research program of the Ministry of Science and Technology (MOST 106-2221-E-366-002), Taiwan (R.O.C).

\section{References}

1 M. Çubuk and M. Gürü: Fuel 88 (2009) 1324.

2 P. Boffetta and I. Burstyn: American J. Ind. Med. 43 (2003) 1.

3 B. Grzegorz, P. Andrzej, and K. Marian: Chemosphere 107 (2014) 23.

4 A. Jullien, V. Gaudefroy, A. Ventura, C. Roche, R. Paranhos, and P. Moneron: Road Mater. Pavement 11 (2010) 149. 
5 J. Turk, A. Mladenovic, F. Knez, V. Bras, A. Sajna, A. Copar, and K. Slanc: J. Cleaner Prod. 81 (2014) 201.

6 F. Lalanne, L. Malhautier, J. C. Roux, and J. L. Fanlo: Bioresour. Technol. 99 (2008) 1699.

7 P. Dwivedi, V. Gaur, A. Sharma, and N. Verma: Purif. Technol. 39 (2004) 23.

8 T. Blankendaal, P. Schuur, and H. Voordijk: J. Clean. 66 (2014) 27.

9 A. Karakaya, B. Yücesoy, A. Turhan, O. Erdem, S. Burgaz, and A. E. Karakaya: Toxicology 135 (1999) 43.

10 P. Cui, S. Wu, Y. Xiao, and H. Zhang: Constr. Build. Mater. 68 (2014) 644.

11 Y. Xiao, M. Ven, A. Molenaar, and S. P. Wu: Constr. Build. Mater. 48 (2013) 59.

12 A. Jullien, P. Monéron, G. Quaranta, and D. Gaillard: Resour. Conserv. Recy. 47 (2006) 356.

13 F. L. Roberts, P. S. Kandhal, E. R. Brown, D. Y. Lee, and T. W. Kennedy: National Asphalt Paving Association Education Foundation (Transportation Research Board, 1996).

14 J. Chen, H. Wang, and L. Li: J. Mater. Civil Eng. 27 (2015) 1943.

15 I. Menapace, W. Yiming, and E. Masad: Fuel 202 (2017) 366. 